\title{
Cerebrospinal fluid soluble L-selectin (sCD62L) in meningoencephalitis
}

\author{
Christoph Bührer, Ralf Herold, Dietger Stibenz, Günter Henze, Michael Obladen
}

\begin{abstract}
The leucocyte adhesion molecule Lselectin (CD62L) is rapidly cleaved off proteolytically after cell activation, generating soluble L-selectin (sCD62L) molecules. sCD62L concentrations were determined in 185 cerebrospinal fluid (CSF) samples obtained from children aged 1 month to 17 years. In 36 CSF samples of children with meningoencephalitis, SCD62L was significantly higher (median $209 \mathrm{fmol} / \mathrm{ml}$ ) than in samples of children with other febrile diseases ( $=67$, median $50 \mathrm{fmol} / \mathrm{ml})$ or non-febrile disorders ( $n=82$, median 44 fmol $/ \mathrm{ml}$ ). There was a positive correlation between CSF protein and CSF sCD62L $\left(r_{s}=0.68\right)$, suggesting that $a$ disturbed blood-brain barrier contributes to raised sCD62L concentrations in the CSF. However, the CSF sCD62L/protein ratio of children with meningoencephalitis was significantly higher than in children with other febrile diseases or non-febrile disorders, indicating that $S C D 62 L$ concentrations in children with meningoencephalitis were higher than expected from plasma leakage alone. It is concluded that both an impaired blood-brain barrier and the generation of SCD62L by infiltrating leucocytes contribute to raised CSF SCD62L concentrations in children with meningoencephalitis.
\end{abstract}

(Arch Dis Child 1996; 74: 288-292)

Keywords: cerebrospinal fluid, soluble L-selectin, meningoencephalitis.

Children's Hospital, Virchow Medical Centre, Humboldt University, Berlin, Germany:

Department of

Neonatology

C Bührer

D Stibenz

M Obladen

Department of Paediatric

Haematology and

Oncology

$R$ Herold

G Henze

Correspondence to: Dr C Bührer, Kinderklinik Virchow-Klinikum, Humboldt-Universität, Forschungshaus R 2.0411, 13353 Berlin, Germany.

Accepted 16 November 1995 bound leucocytes ${ }^{2}$ which precedes leucocyte extravasation. Following cell activation, CD62L is rapidly cleaved off, ${ }^{34}$ and shed soluble Lselectin (sCD62L) appears in the surrounding fluid as $62 \mathrm{kDa}$ and $75-100 \mathrm{kDa}$ fragments with preserved ligand binding capacity. ${ }^{5}$ It has been reported that plasma or serum $\mathrm{SCD} 62 \mathrm{~L}$ concentrations were increased in patients with insulin dependent diabetes mellitus, ${ }^{6}$ acquired immunodeficiency syndrome, ${ }^{7}$ and a proportion of patients with acute leukaemia, 8 while decreased $\mathrm{sCD} 62 \mathrm{~L}$ was found in premature newborn infants ${ }^{910}$ and neutropenic patients after bone marrow transplantation. ${ }^{11}$ Low concentrations of $\mathrm{sCD} 62 \mathrm{~L}$ have also been detected in cerebrospinal fluid (CSF), with marked elevations in patients with meningeal leukaemia. ${ }^{12}$ The aim of this study was to determine whether sCD62L concentrations were increased in the CSF in children with acute inflammatory central nervous system (CNS) diseases.

\section{Material}

PATIENTS

sCD62L concentrations were measured in 185 CSF leftovers of samples submitted to the routine paediatric laboratory between January 1993 and August 1994. The analysis was restricted to children between 1 month (corrected for prematurity) and 17 years of age without haemorrhagic or neoplastic CNS diseases. Blood contaminated CSF samples $(>30$ red blood cells $/ \mu \mathrm{l}$ ) were excluded.

Samples were retrospectively allocated to three diagnostic categories: diagnostic lumbar puncture during sepsis work-up or after a febrile seizure, without a subsequent diagnosis of inflammatory CNS disease $(n=67)$; nonfebrile, non-pleocytotic disorders, such as Bell's palsy, mental retardation, or suspected metabolic disease $(n=82)$; and acute inflammatory CNS diseases (meningitis, encephalitis, or meningoencephalitis, henceforth referred to as meningoencephalitis, $n=36$ ). Diagnostic criteria for the last group were fever, clinical signs of meningeal irritation or increased intracranial pressure, and CSF pleocytosis ( $>8$ nucleated cells $/ \mu \mathrm{l})$. Ten of these 36 samples were from cases with bacterial aetiology, while in the other 26 samples meningoencephalitis was presumed to have resulted from viral infection.

The average age was lower $(p<0.05)$ in the group of febrile children without CNS inflammation [median (10-90th centile range): 24 (3-122 months)] than in the groups of children with meningoencephalitis [67 (3-122 months)] and non-febrile disorders [62 (3-177 months)], while the latter two groups did not differ significantly with respect to age $(p>0 \cdot 1)$.

Centrifuged CSF samples were stored frozen at $-20^{\circ} \mathrm{C}$ and analysed within 3 months. Immunoreactive sCD62L has been shown to be exceptionally stable during prolonged storage and after repeated freezing and thawing. ${ }^{5}$ CD62L concentrations were determined by a luminescence based sandwich ELISA as described previously, ${ }^{9}$ with an assay sensitivity of $17 \mathrm{fmol} / \mathrm{ml}$ (negative control $+3 \mathrm{SD}$ ). Samples were diluted with an equal amount of buffer, or more if the first measurement yielded an sCD62L concentration above the upper end of the linear range of the assay 


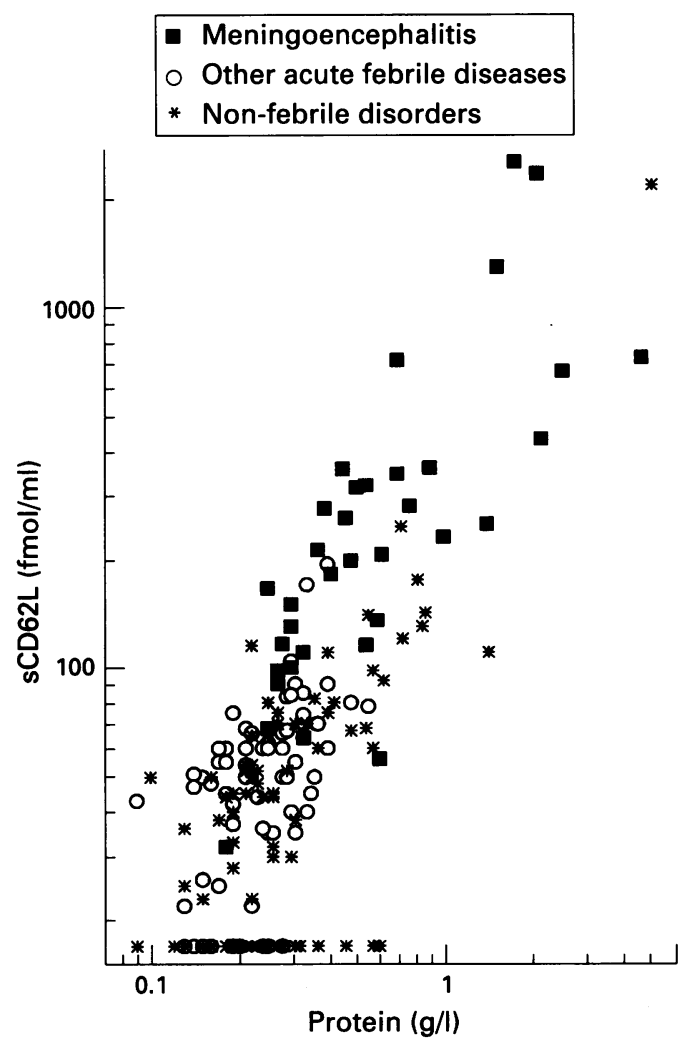

Figure 1 Cerebrospinal fluid protein content ( $X$ axis) and sCD62L concentrations ( $Y$ axis) in children with acute meningoencephalitis, other febrile diseases, and non-febrile, non-pleocytotic disorders.

$(100 \mathrm{fmol} / \mathrm{ml})$. CSF protein content was determined by the biuret method.

\section{STATISTICAL ANALYSIS}

Non-parametric statistical tests with two sided $p$ values were used throughout and were based on a significance level of $0 \cdot 05$. Results of groups are expressed as median and 10-90th centile range. Differences between groups were assessed by the Wilcoxon or Kruskal-Wallis test. The Kolmogorov-Smirnov goodness of fit test was used to assess normal (Gaussian) distribution. Spearman rank order correlation coefficients $\left(r_{s}\right)$ were calculated to measure the strength of association between numerical variables. Sensitivity, specificity, and positive and negative predictive values were calculated for different cut off points, and the area under a receiver operating characteristic (ROC) curve which plots sensitivity versus 1 -specificity was used to estimate diagnostic accuracy. ${ }^{13}$

\section{Results}

SCD62L IN CSF

In CSF samples of febrile children who underwent a diagnostic lumbar puncture but were not found to have signs of inflammatory CNS disease, sCD62L concentrations ranged from $<17 \mathrm{fmol} / \mathrm{ml}$ (detection limit of the assay) to $194 \mathrm{fmol} / \mathrm{ml}$, with a median of $50 \mathrm{fmol} / \mathrm{ml}$ and a 10-90th centile range of 17 to $84 \mathrm{fmol} / \mathrm{ml}$ (fig 1). The distribution of $\mathrm{sCD} 62 \mathrm{~L}$ concentrations did not differ significantly from a normal distribution $(p>0 \cdot 1)$. CSF sCD62L concentrations in children without acute febrile disease [median (10-90th centile range): 44 (17-119 $\mathrm{fmol} / \mathrm{ml})$ ] lacked a normal distribution $(\mathrm{p}<0.0001)$ but did not differ significantly from those of children with febrile disorders without CNS inflammation ( $p>0 \cdot 1)$. In contrast, CSF samples of children with meningoencephalitis [median (10-90 percentile range): $209(62-888 \mathrm{fmol} / \mathrm{ml})]$ had significantly higher sCD62L concentrations $(p<0 \cdot 0001$, for comparisons to both control groups), with a distribution differing significantly from normal $(\mathrm{p}<0.01)$.

In samples of children with meningoencephalitis, there was a positive correlation between CSF nucleated cell counts and sCD62L levels $\left(r_{s}=0.61, p<0.001\right) . s C D 62 L$ concentrations were significantly $(p<0.0001)$ higher in CSF samples of meningoencephalitis of bacterial origin [685 $(257-482 \mathrm{fmol} / \mathrm{ml})]$ than in viral meningoencephalitis [143 (49-331 $\mathrm{fmol} / \mathrm{ml})]$, as were nucleated cell counts [ 2700 (49-7756) cells/1 $v 110(15-780)$ cells $/ \mu l]$.

There was no significant association between the child's age at the time of lumbar puncture and sCD62L concentrations in the whole study group or in the two subgroups of children without pleocytosis. In children with meningoencephalitis, CSF sCD62L concentrations (but not nucleated cell counts) appeared to decrease with chronological age $\left(r_{s}=-0.51, p<0.01\right)$.

\section{CSF PROTEIN CONTENT AND SCD62L/PROTEIN} RATIO

The CSF protein content was significantly higher $(p<0.0001)$ in children with meningoencephalitis (median $490 \mathrm{mg} / \mathrm{l}, 10-90$ th centile range $250-2088 \mathrm{mg} / \mathrm{l}$ ) than in children with non-febrile disorders [250 (150-614) $\mathrm{mg} / \mathrm{l}]$ and children with other febrile diseases [250 (148-362) $\mathrm{mg} / \mathrm{l}$. A significant association $(p<0.001)$ was found between CSF protein content and SCD62L concentrations within the total study population $\left(r_{s}=0.68\right)$ and within the three diagnostic groups (meningoencephalitis: $r_{s}=0.80$; other febrile diseases: $r_{s}=0.56$, nonfebrile disorders: $\left.r_{s}=0.54\right)$. However, the CSF $\mathrm{sCD} 62 \mathrm{~L}$ protein ratio was higher $(\mathrm{p}<0.0001)$ in children with meningoencephalitis $[0.385$ $(0 \cdot 171-0.902)]$ than in children with other febrile diseases $[0.212(0.098-0.348)]$ and children with non-febrile disorders $[0.166$ (0.064-0.290)]. The CSF protein content was higher $(p<0.0001)$ in samples from children with bacterial meningoencephalitis [1626 (519-4464) $\mathrm{mg} / \mathrm{l}]$ than in children with viral meningoencephalitis [380 (232-799) $\mathrm{mg} / \mathrm{l}$ ], while the CSF sCD62L/protein ratio did not differ significantly $(\mathrm{p}>0.1)$ between the two groups [bacterial: $0.565(0 \cdot 156-1.405)$; viral: $0.366(0 \cdot 152-0 \cdot 677)]$.

CSF SCD62L AND SCD62L/PROTEIN RATIO AS DIAGNOSTIC INDICES

In CSF of children with acute febrile diseases (with and without CNS inflammation), an sCD62L cut-off value of $98 \mathrm{fmol} / \mathrm{ml} \max -$ imised the sum of sensitivity plus specificity for 


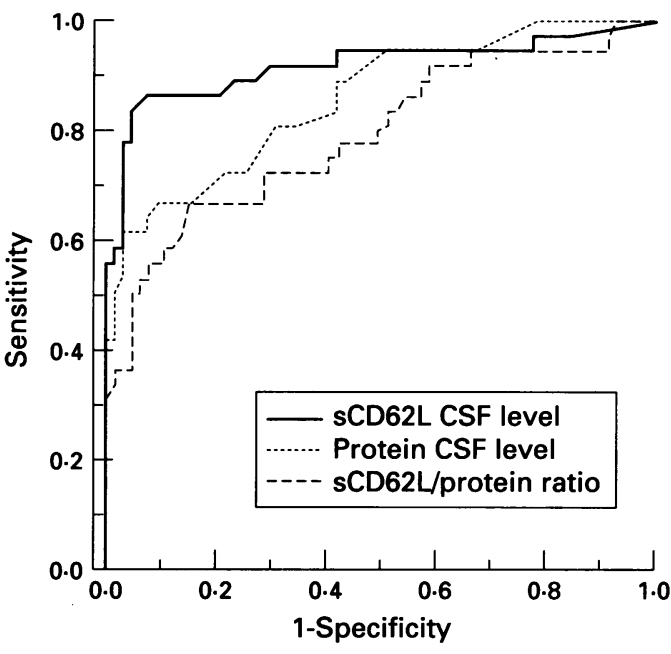

Figure 2 Receiver operator characteristic curves of cerebrospinal fluid sCD62L concentrations, protein concentrations, and $s C D 62 \mathrm{~L} /$ protein ratio plotting sensitivity versus 1 -specificity to discriminate between febrile children with and without meningoencephalitis.

the diagnosis of acute CNS inflammatory disease. Thirty of 36 children with meningoencephalitis had sCD62 concentrations of $>98 \mathrm{fmol} / \mathrm{ml}$ (sensitivity 0.83 ); of $33 \mathrm{CSF}$ samples with sCD62L concentrations of $>98$ $\mathrm{fmol} / \mathrm{ml}, 30$ were from children with meningoencephalitis (positive predictive value 0.91 ). Sixty four of 67 febrile children without CNS inflammation had sCD62 concentrations of $<98 \mathrm{fmol} / \mathrm{ml}$ (specificity 0.96 ); of $70 \mathrm{CSF}$ samples with $\mathrm{sCD} 62 \mathrm{~L}$ concentrations of $<98$ $\mathrm{fmol} / \mathrm{ml}, 64$ were from children without CNS inflammation (negative predictive value 0.91 ). The maximised cut-off value of the sCD62L/protein ratio was 0.333 , yielding a sensitivity of 0.67 , a specificity of 0.85 , and positive and negative predictive values of 0.71 and 0.83 , respectively. The area under the ROC curve (fig 2) was 0.92 for $\mathrm{sCD} 62 \mathrm{~L}$, and 0.79 for the sCD62L/protein ratio. For comparison, the area under the ROC curve was 0.86 for the CSF protein level.

When all CSF samples analysed were taken into account, the $\mathrm{sCD} 62 \mathrm{~L}$ cut-off value maximising the sum of sensitivity plus specificity for the diagnosis of acute CNS inflammatory disease was $90 \mathrm{fmol} / \mathrm{ml}$. Sensitivity was $0 \cdot 86$, specificity was 0.88 , and positive and negative predictive values were 0.63 and 0.96 , respectively. The maximising $\mathrm{sCD} 62 \mathrm{~L} /$ protein ratio cut-off value 0.333 was associated with a sensitivity of 0.67 , a specificity of 0.90 , and positive and negative predictive values of 0.62 and 0.92 , respectively. The area under the ROC curve was 0.91 for $\mathrm{SCD} 62 \mathrm{~L}$, and 0.83 for the $\mathrm{SCD} 62 \mathrm{~L} /$ protein ratio.

CSF nucleated cell counts, SCD62L concentrations, and protein content had a similar diagnostic accuracy in discriminating between bacterial and viral meningoencephalitis, while the $\mathrm{sCD} 62 \mathrm{~L} /$ protein ratio was not helpful in distinguishing between the two aetiologies. The area under the ROC curve was 0.88 for the CSF nucleated cell count, 0.95 for the CSF protein content, and 0.96 for CSF sCD62L levels. The cut-off points of 400 nucleated cells $/ 1,0.690 \mathrm{mg}$ protein $/ \mathrm{l}$, and $316 \mathrm{fmol}$
sCD62L/ml were each associated with a sensitivity of 0.90 , a specificity of 0.89 , a positive predictive value of $0 \cdot 75$, and a negative predictive value of 0.96 .

\section{Discussion}

Under normal conditions, the bulk of CSF proteins derives from ultrafiltration of plasma across the blood-brain barrier. While no reference range for plasma $\mathrm{SCD} 62 \mathrm{~L}$ concentrations in children has been published yet, sCD62L values have been found to be $12 \cdot 4$ (SD 2.1) $\mathrm{pmol} / \mathrm{ml}$ in adult cubital vein plasma, and 8.5 $(2 \cdot 2) \mathrm{pmol} / \mathrm{ml}$ in umbilical cord vein plasma ${ }^{9}$ employing the same assay as that used here to determine CSF sCD62L concentrations. In children with febrile diseases without evidence of inflammatory CNS disease, presumed to have neither a disturbance of the blood-brain barrier nor production of $\mathrm{sCD} 62 \mathrm{~L}$ within the CNS, the estimated sCD62L plasma/CSF ratio (approximately 170-250:1) appears to be similar to that of most other proteins. ${ }^{14}$ While a simultaneous determination of $\mathrm{sCD} 62 \mathrm{~L}$ in both plasma and CSF in the same patient to specifically address this question was not performed, the correlation between CSF sCD62L concentrations and CSF protein content suggests that injury to the blood-brain barrier increases CSF sCD62L concentrations alongside CSF protein concentrations.

In addition to reaching the CSF by ultrafiltration, some proteins are also produced within the CNS, such as immunoglobulins, $\beta_{2}$ microglobulin, transthyretin (prealbumin), transferrin, and inflammatory cytokines. ${ }^{15-17}$ The investigation presented here suggests that during acute inflammatory CNS diseases, sCD62L is also actively released by cells within the CNS, since the increase in CSF sCD62L markedly exceeds that of CSF protein. Leucocytes are the only cell type known to express CD62L, and infiltrating leucocytes are the most likely source of locally produced sCD62L. After activation both in vitro and in vivo, leucocytes of lymphoid and myeloid origin alike are characterised by loss of their of surface expressed CD62L. ${ }^{3} 4$ 18-20

Although a positive correlation was found between CSF nucleated cell counts and CSF sCD62L levels, the leucocytes suspended in the CSF at the time of lumbar puncture can be expected to contribute only a minor fraction of CSF sCD62L. Assuming there are approximately $30000 \mathrm{CD} 62 \mathrm{~L}$ molecules per unstimulated leucocyte, ${ }^{21}$ even complete shedding of CD62L within the CSF compartment would result in no more than $5 \times 10^{-5} \mathrm{fmol} \mathrm{sCD62L}$ per cell. The upper limit of the proportion of sCD62L shed from leucocytes in the CSF sample can be calculated to be $3 \cdot 8 \%$ (10-90th centile range $1 \cdot 1 \%-49 \cdot 3 \%$ ). As a highly glycated glycoprotein, sCD62L is easily soluble in aqueous solutions; thus both leucocytes suspended in CSF and an unknown number of leucocytes attached to neuronal and glial structures may contribute to CSF sCD62L. Since it is well documented that shedding of sCD62L from leucocytes is largely 
accelerated upon stimulation, ${ }^{34}$ sCD62L production reflects the number of infiltrating leucocytes as well as their state of activation. In addition, CSF sCD62L concentrations may also be influenced by the duration of the inflammatory process. Owing to the lack of data regarding the half life of sCD62L in CSF (at $37^{\circ} \mathrm{C}$ ), accumulation of $\mathrm{sCD} 62 \mathrm{~L}$ produced by repetitive waves of infiltrating leukocytes in the CSF over time remains a matter of speculation.

The predominant infiltrating leucocytes in acute meningoencephalitis of bacterial and viral origin, neutrophils and lymphocytes respectively, require different signals for downregulation of CD62L surface expression in vitro. Neutrophils shed their surface expressed CD62L molecules within minutes after contact with soluble mediators of inflammation, such as interleukin-1 or tumour necrosis factor- $\alpha^{3}$ which have been shown to be present in CSF during acute bacterial meningoencephalitis. ${ }^{172223}$ In contrast, lymphocyte CD62L shedding does not occur in response to the above mentioned cytokines or interferon- $\gamma$, appears to require prolonged antigenic stimulation, and may take several hours to be complete. ${ }^{24}$ Thus both the distinct signalling cascades involved and the disparate number of infiltrating leucocytes may contribute to the difference in CSF sCD62L concentrations observed in bacterial and viral meningoencephalitis.

The results in children with febrile diseases without CNS inflammation may be used to define a reference value of $\mathrm{SCD} 62 \mathrm{~L}$ concentrations in the CSF. However, none of the assays currently employed to quantitate sCD62L in biological fluids appears to have been sufficiently standardised by recombinant or highly purified natural $\mathrm{sCD} 62 \mathrm{~L}$, and there is some discrepancy as to the normal sCD62L serum range. ${ }^{5-10}$ Some investigators prefer to express their data as relative units. ${ }^{6} 11$ While conclusions drawn from measurements with the same assay system are not affected by this problem, definitive reference values will have to await comparative testing of recombinant or highly purified natural sCD62L. In addition, sCD62L found in human body fluids is actually composed of various molecular species with molecular weights ranging from 62 to 100 $\mathrm{kDa},{ }^{5}$ most probably because of variable glycation of the protein core. Since the monoclonal antibodies used in several ELISA systems do not discriminate between the various SCD62L isoforms generated by differential glycation, the common practice of conversion of ELISA generated data from $\mathrm{fmol} / \mathrm{ml}$ to $\mathrm{ng} / \mathrm{ml}$ is inaccurate $(100 \mathrm{fmol} / \mathrm{ml}$ may correspond to anything between $6 \cdot 2$ and $10 \mathrm{ng} / \mathrm{ml}$ ).

The area under the ROC curves for CSF sCD62L and the CSF sCD62L/protein ratio shows that both variables are fairly accurate in distinguishing children with and without meningoencephalitis. In addition, CSF sCD62L levels but not the CSF sCD62L/protein ratio discriminates between bacterial and viral meningitis. However, the sandwich ELISA used in this study takes four to five hours, and necessary treatment would have to be instituted well before that time. This drawback is shared by investigations reporting raised CSF concentrations of other proteins in meningoencephalitis of bacterial or viral origin, such as $\beta_{2}$ microglobulin, tumour necrosis factor $\alpha$, interleukin-1 $\beta$, interleukin- 6 , interferon- $\gamma$, or granulocyte colony stimulating factor. ${ }^{15222325}$ To establish the presence or absence of biologically significant changes, virtually all studies including this one referred to cases of acute meningoencephalitis. The results should encourage further investigation into subacute, chronic, or relapsing forms of inflammatory CNS disease, where additional measurements might not only provide useful ancillary diagnostic tools but also help to gain further insight into the mechanisms of disease.

This work was supported in part by grants from the German research council (DFG, Bu 623/2-3) and the Liselotte Beutel foundation. Special thanks to Traute Burmeester and her team for logistical assistance, and to Prof Eugene $C$ Butcher $M D$, Stanford University, Palo Alto, California, for his gift of monoclonal antibodies used in the sCD62L ELISA.

1 Ley K, Gaethgens P, Fennie C, Singer MS, Lasky LA Rosen SD. Lectin-like cell adhesion molecule 1 mediates leukocyte rolling in mesenteric venules in vivo. Blood 19ukocyte rolling $2553-5$.

2 Bargatze RF, Kurk S, Butcher EC, Jutila M. Neutrophils roll on adherent neutrophils bound to cytokine-induced endothelial cells via L-selectin on the rolling cells. $\mathcal{F}$ Exp Med 1994; 180: 1785-92.

3 Kishimoto TK, Jutila MA, Berg EL, Butcher EC. Neutrophil Mac-1 and MEL-14 adhesion proteins inversely regulated by chemotactic factors. Science 1989 245: 1238-41.

4 Bührer C, Berlin C, Thiele H-G, Hamann A. Lymphocyte activation and expression of the human leucocyteendothelial cell adhesion

5 Schleifenbaum B, Spertini O, Tedder TF. Soluble L-selectin is present in human plasma at high levels and retains functional activity. $f$ Cell Biol 1992; 19: and retains.

6 Lampeter E, Kishimoto TK, Rothlein R, et al. Elevated levels of circulating adhesion molecules in IDDM patients and in subjects at risk for IDDM. Diabetes 1992; 41: 1668-71.

7 Spertini O, Schleiffenbaum B, White-Owen C, Ruiz P, Tedder TF. ELISA for quantitation of L-selectin shed from leukocytes in vivo. $\mathcal{f}$ Immunol Methods 1992; 156: 115-23.

8 Spertini O, Callegari P, Cordey A-S, et al. High levels of the shed form of L-selectin are present in patients with acute leukemia and inhibit blast cell adhesion to activated endothelium. Blood 1994; 84: 1249-56.

9 Bührer C, Stibenz D, Graulich J, et al. Soluble L-selectin (sCD62L) umbilical cord plasma levels increase with gestational age. Pediatr Res 1995; 38: 336-41.

10 Rebuck N, Gibson A, Finn A. Neutrophil adhesion molecules in term and preterm infants: normal or enhanced cules in term and preterm infants: normal or enhanced shedding. Clin Exp Immunol 1995; 10: 183-9.

11 Zetterberg E, Richter J. Correlation between serum level of Zetterberg E, Richter J. Correlation between serum level of
soluble L-selectin and leukocyte count in chronic myeloid and lymphocytic leukemia and during bone marrow transplantation. Eur $\mathcal{F}$ Hematol 1993; 51: 113-9.

12 Stucki A, Cordey A-S, Monai N, de Flaugergues J-C, Schapira M, Spertini O. Cleaved L-selectin concentrations in meningeal leukemia. Lancet 1995; 345: 286-9.

13 Hanley JA, McNeil BJ. The meaning and use of the area under a receiver operating characteristic (ROC) curve. Radiology 1982; 143: 29-36.

14 Weisner B, Kauerz U. The influence of the choroid plexus on the concentration of prealbumin in CSF. $\mathcal{F}$ Neurol Sci 1983; 61: 27-35.

15 García-Alix A, Martín-Ancel A, Ramos MT, et al. Cerebrospinal fluid $\beta_{2}$-microglobulin in neonates with central nervous system infections. Eur $\mathcal{F}$ Pediatr 1995; 154: central ne9-13.

16 Stauder AJ, Dickson PW, Aldred AR, Schreiber G, Mendelsohn FAO, Hudson P. Synthesis of transthyretin (pre-albumin) mRNA in choroid plexus epithelial cells, (pre-albumin) mRNA in choroid plexus epithelial cells, localized by in situ hybridizat

17 Waage A, Halstensen A, Shalaby R, Brandtzaeg P, Kierulf P, Espevik T. Local production of tumor necrosis factor a, interleukin 1 , and interleukin 6 in meningococcal meningitis. F Exp Med 1989; 170: 1859-67.

18 Bührer C, Luxenburger U, Metze B, et al. Diminished cord blood lymphocyte L-selectin expression in neonatal

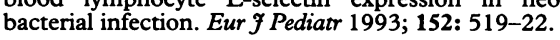


19 Török C, Lundahl J, Hed J, Lagercrantz H. Diversity in regulation of adhesion molecules (Mac-1 and L-selectin) in monocytes and neutrophils from neonates and adults. Arch Dis Child 1993; 68: 561-5.

20 Bührer C, Graulich J, Stibenz D, Dudenhausen JW, Obladen $M$. L-selectin is downregulated in umbilical cord blood granulocytes and monocytes of newborn infants with acute bacterial infection. Pediatr Res 1994; 36: 799-804.

21 Anderson DC, Abbassi O, Kishimoto TK, Koenig JM McIntire LV, Smith CW. Diminished lectin- epidermal growth factor-, complement binding domain-cell adhesion molecule-1 on neonatal neutrophils underlies their impaired CD18-independent adhesion to endothelial cells in vitro. F Immunol 1991; 146: 3372-9.

22 Kornelisse RF, de Groot R, Neijens HJ. Bacterial meningitis: mechanisms of disease and therapy. Eur $\mathcal{f}$ Pediatr 1994; 154: 85-96.

23 Ohga S, Aoki T, Okada K, et al. Cerebrospinal fluid concentrations of interleukin- $1 \beta$, tumour necrosis factor- $\alpha$, and interferon gamma in bacterial meningitis. Arch Dis Child 1994; 70: 124-5.

24 Bührer C, Berlin C, Jablonski-Westrich D, Holzmann B, Thiele H-G, Hamann A. Lymphocyte activation and regulation of three adhesion molecules with supposed function in homing: LECAM-1 (MEL-14 antigen) LPAM-1/2 ( $\alpha 4$-integrin) and CD44 (Pgp-1). Scand $\mathscr{f}$ Immunol 1992; 35: 107-20. 25 Fukushima K, Ishiguro A, Shimbo T. Transient elevation of brospinal fluid at the initial stage of aseptic meningitis in children. Pediatr Res 1995; 37: 160-4.

\section{Multiple sclerosis}

The Grampian region of Scotland has the highest recorded incidence of multiple sclerosis in the world. A register in Aberdeen includes 1489 cases and 28 of these had an onset of the disease before the age of 16 years. Data have recently been presented about these 28 patients (G F Cole and C A Stuart, Developmental Medicine and Child Neurology 1995; 37: 661-6).

Seven children had their first symptoms before the age of 10 and 21 between ages 10 and 15 years. Two were aged 1 and 2 years but the rest were 6 or over. The features of the disease were similar to those seen in adults but 11 children had a systemic illness at the onset which is uncommon in adults. Presenting features were: limb, bulbar or facial weakness (15), visual blurring (10), sensory loss (9), ataxia (3), bladder dysfunction (3), vertigo (2), and encephalopathy (2). A second episode occurred within a year in 17 patients but the longest interval was 25 years. Useful investigations were those used in adults: magnetic resonance imaging, visual evoked responses, and cerebrospinal fluid examination for IgG and oligoclonal bands.

On the whole the prognosis for children seemed somewhat better than for adults. Fifteen patients were well after follow up for between three and over 30 years. Eight died from three to 43 years after the onset. Four patients had a steadily progressive course from the onset. Twenty one had a relapsing-remitting course all along and two developed a progressive illness after a period of relapsing-remitting. One was lost to follow up.

One child aged 13 months at onset had a progressive course and died aged 9 and another aged 2 years at onset had a relapsing-remitting course and was well at the age of 15 years ( $\mathrm{G} \mathrm{F}$ Cole and colleagues, Developmental Medicine and Child Neurology 1995; 37: 667-72).

Multiple sclerosis may occur at any age past infancy and paediatricians should be prepared to consider the diagnosis, perhaps before the classical 'dissemination of lesions in space and time' has occurred.

ARCHIVIST 